\title{
Penerapan Metode Multi Attribute Utility Theory untuk Menganalisa Pemberian Bantuan Raskin
} Implementation of Multi Attribute Utility Theory to Analyze Rice Aid Beneficiary

\author{
Alfiarini ${ }^{1}$, Yogi Primadasa ${ }^{2}$ \\ ${ }^{1,2}$ Program Studi Sistem Informasi, STMIK Bina Nusantara Jaya Lubuklinggau, \\ Jl. Yos Sudarso No.97A Kota Lubuklinggau \\ Email: alfiarini3@gmail.com¹,yogiak45@gmail.com²
}

\begin{abstract}
Abstrak
Program beras miskin (Raskin) merupakan subsidi pangan yang diperuntukkan bagi keluarga miskin sebagai upaya dari pemerintah untuk meningkatkan ketahanan pangan dan memberikan perlindungan pada keluarga miskin. Penyaluran dan Pelaksanaan RASKIN bertujuan untuk memperkuat ketahanan pangan rumah tangga terutama rumah tangga miskin. Kelurahan Dempo Kecamatan Lubuklinggau Timur II Kota Lubuklinggau, mendapatkan kewajiban dan bertugas untuk menyalurkan beras rumah tangga miskin (Raskin) kepada masyarakat. Dengan melakukan observasi langsung, dalam upaya penyaluran raskin di Kelurahan Dempo mengalami beberapa kendala, seperti seleksi penerimaan bantuan raskin dilakukan dengan cara langsung memberi bantuan raskin kepada RTS ( Rumah Tanggan Sasaran) yang mana penulis anggap kurang tepat. Selain itu juga dalam penentuan kriteria yang masih di lihat dari beberapa aspek yang peneliti anggap masih kurang tepat sasaran. Dengan mengkaji ulang dalam penentuan kriteria penerimaan kelayakan raskin Setelah di dapatkan kriteria empat kriteria yang valid, dan dengan menggunakan 20 kepala keluarga sebagai simulasi penulis melakukan analisa sistem pendukung keputusan menggunakan metode Multi Attirbute Unility Theory (MAUT). Dari hasil perhitungan nilai evaluasi, sepuluh kepala keluarga dengan nilai tertinggi adalah yang berhak menerima bantuan raskin.
\end{abstract}

Kata kunci: Raskin, Multi Attirbute Unility Theory(MAUT), Sistem Pendukung Keputusan

\begin{abstract}
Abstrak
The poor rice program (Raskin) is a food subsidy intended for poor families as an effort from the government to improve food security and provide protection for poor families. Distribution and Implementation of RASKIN aims to strengthen household food security, especially for poor households. Dempo Village, Lubuklinggau Timur II Subdistrict, Lubuklinggau City, has an obligation and has the duty to distribute poor household rice (Raskin) to the community. By conducting direct observation, in the effort to distribute Raskin in Dempo Village, there were several obstacles, such as selection of receiving Raskin assistance by directly giving Raskin assistance to RTS (Targeted Target Houses) which the authors deemed inappropriate. In addition, in determining the criteria that are still seen from several aspects that researchers consider still not well targeted. By reviewing the determination of the eligibility criteria for Raskin eligibility. After obtaining the criteria of four valid criteria, and by using 20 households as simulation, the writer analyzes the decision support system using the Multi-Attitude Unity Theory (MAUT) method. From the results of the
\end{abstract}


calculation of the evaluation value, the ten families with the highest scores are those who are entitled to receive Raskin aid.

Keywords: Raskin, Multi Attirute Unility Theory (MAUT), Decision Support System.

\section{PENDAHULUAN}

Program beras miskin (Raskin) merupakan subsidi pangan yang diperuntukkan bagi keluarga miskin sebagai upaya dari pemerintah untuk meningkatkan ketahanan pangan dan memberikan perlindungan pada keluarga miskin. Peraturan Presiden Republik Indonesia nomor 15 tahun 2010 tentang Percepatan Penanggulangan Kemiskinan dan Intruksi Presiden nomor 3 tahun 2010 tentang program pembangunan yang berkeadilan. Bahwa raskin merupakan salah satu dari berbagai program-program pro rakyat yang di luncurkan oleh pemerintah Indonesia sebagai upaya percepatan penanggulangan kemiskinan. Pemerintah berharap dengan adanya bantuan beras miskin atau raskin dapat berdampak langsung terhadap peningkatan kesejahteraan keluarga miskin yang ada di indonesia.Program ini diatur dalam Undang-Undang No.7 Tahun 1996, tentang Pangan dan Peraturan Presiden RI No.13 Tahun 2009 tentang Koordinasi Penanggulangan Kemiskinan.

Penyaluran dan Pelaksanaan RASKIN bertujuan untuk memperkuat ketahanan pangan rumah tangga terutama rumah tangga miskin[1]. Fungsi RASKIN di perluas dengan menjadikan program perlindungan sosial masyarakat. Melalui sebuah kajian ilmiah, penamaan RASKIN menjadi nama program diharapkan akan menjadi lebih tepat sasaran dan mencapai tujuan RASKIN[2].

Kelurahan Dempo Kecamatan Lubuklinggau Timur II Kota Lubuklinggau, mendapatkan kewajiban dan bertugas untuk menyalurkan beras rumah tangga miskin (Raskin) kepada masyarakat. Dengan melakukan observasi langsung, dalam upaya penyaluran raskin di Kelurahan Dempo mengalami beberapa kendala, seperti seleksi penerimaan bantuan raskin dilakukan dengan cara langsung memberi bantuan raskin kepada RTS ( Rumah Tanggan Sasaran) yang mana penulis anggap kurang tepat. Selain itu juga dalam penentuan kriteria yang masih di lihat dari beberapa aspek yang peneliti anggap masih kurang tepat sasaran. Dengan mengkaji ulang dalam penentuan kriteria penerimaan kelayakan raskin, peneliti melakukan wawancara langsung kepada 10 kepala Rt. Dari wawancara 10 kepala RT didapatkan 10 kriteria yang menjadi pendukung penilaian, selanjutnya peneliti melakukan uji validitas terhadap 10 kriteria tersebut untuk mendapatkan kriteria yang valid. Setelah didapatkan kriteria yang valid maka penulis melakukan analisa sistem pendukung keputusan menggunakan metode Multi Attirbute Unility Theory.

Sistem pendukung keputusan dapat membantu dari masalah pengambilan keputusan yang tidak terstruktur[3]. Metode multi attribute unility theory sendiri merupakan skema evaluasi akhir dimana objek di definisikan sebagai bobot yang dijumlahkan dengan suatu nilai yang relevan terhadap nilai dimensinya[4][5][6].

Peneleitian sebelumnya proses seleksi calon penerima bantuan menggunakan metode MAUT, dengan menggunakan 3 kriteria serta 100 sampel dan didapatkan hasil akurasi sebesar $80 \%$ [7]. Adanya keterkaitan pada penelitian ini adalah, samasama menyeleksi calon penerima bantuan menggunakan metode MAUT. Selanjutnya penelitian tentang penerapan metode MAUT dalam pemilihan rumah kost menyimpulkan metode MAUT mampu memberi saran atau rekomendasi dalam pemilihan rumah kost secara objektif[8]. Penelitian selanjutnya pada tahun 2019 
dalam penentuan penerimaan raskin menggunakan metode AHP kriteria yang dipakai yaitu pekerjaan, penghasilan, tanggungan, kondisi rumah dan hasil yang didapatkan berupa informasi perangkingan hasil[9]. Selanjutnya penelitian pada tahun 2019 penentuan penerimaan raskin menggunakan metode SAW menyimpulkan bahwa hasil yang didapatkan dapat membantu proses pelaksanaan pemberian bantuan raskin berdasarkan nilai terbesar sehingga memudahkan pengambil keputusan untuk memilih alterbatif terbaik dari sejumlah alternatif[10]. Pada penelitian tahun 2018 algoritma MAUT pada destinasi tujuan wisata lokal menyimpulkan bawah metode MAUT mampu menghasilkan pilihan yang lebih objektif dengan nilai hasil tertinggi sebagai rekomendasi destinasi tujuan wisata lokal.[11]

\section{METODOLOGI PENELITIAN}

Dalam pengerjaan penelitian ini, penulis melakukan tahapan atau langkah sebagai berikut :

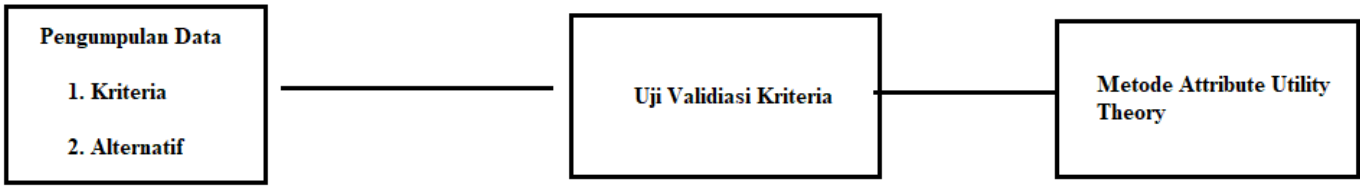

Gambar 1 Metodologi Penelitian

\subsection{Pengumpulan Data}

Pada tahapan pengumpulan data , dari hasil wawancara kepada masing-masing ketua Rt, didapatkan masing-masing $1 \mathrm{Rt}$ untuk $10 \mathrm{KK}$ yang mendapatkan bantuan raskin dari 20 nama KK yang diajukan masing-masing ketua Rt, yang mana dari $20 \mathrm{KK}$ nantinya dijadikan sebagai alternatif penerima bantuan raskin.

Untuk data nama KK yang menjadi alternative sebagai simulasi dalam menganalisa pemberian bantuan peneliti menggunakan data KK pada Rt.01 yang mana data tersebut dapat dilihat pada tabel 1 di bawah ini :

Tabel 1 Alternatif / KK

\begin{tabular}{|l|l|l|}
\hline No & Nama Alternatif/ KK & Rt \\
\hline 1 & Suhardi & 01 \\
\hline 2 & Ahmadi & 01 \\
\hline 3 & Rahmat & 01 \\
\hline 4 & Eva & 01 \\
\hline 5 & Endang & 01 \\
\hline 6 & Edi & 01 \\
\hline 7 & Ariyandie & 01 \\
\hline 8 & Solimin & 01 \\
\hline 9 & Siti & 01 \\
\hline 10 & Pranita & 01 \\
\hline 11 & Hengki & 01 \\
\hline 12 & Julianti & 01 \\
\hline 13 & Rini & 01 \\
\hline 14 & Suharti & 01 \\
\hline 15 & Bella & 01 \\
\hline 16 & Yudi & 01 \\
\hline 17 & Topan & 01 \\
\hline
\end{tabular}




\begin{tabular}{|l|l|l|}
\hline 18 & Guntur & 01 \\
\hline 19 & Ansori & 01 \\
\hline 20 & Mirza & 01 \\
\hline
\end{tabular}

Selanjutnya data yang berkaitan dengan pemberian bantuan raskin, dari hasil observasi dan wawancara kepada 10 kepala Rt peneliti mendapatkan 10 kriteria yang mempengaruhi pemberian bantuan raskin. Kriteria yang mempengaruhi pemberian bantuan raskin dapat dilihat pada tabel 1 di bawah ini :

Tabel 2 Kriteria

\begin{tabular}{|l|l|l|}
\hline No & Nama Kriteria & Simbol \\
\hline 1 & Penghasilan & K1 \\
\hline 2 & Fasilitas Air Bersih & K2 \\
\hline 3 & Jumlah Tanggungan & K3 \\
\hline 4 & Luas Bangunan & K4 \\
\hline 5 & Aset Pribadi & K5 \\
\hline 6 & Aliran Listrik & K6 \\
\hline 7 & Pekerjaan & K7 \\
\hline 8 & Bahan Bakar & K8 \\
\hline 9 & Dinding Rumah & K9 \\
\hline 10 & Atap Rumah & K10 \\
\hline
\end{tabular}

\subsection{Uji Validasi Kriteria}

Dari 10 kriteria tersebut peneliti melakukan analisa menggunakan uji validiasi dengan menyebarkan kuisioner untuk di bagikan kepada 10 ketua RT, yang mana instrument penilaian menggunakan skala likert dengan 4 pilihan yaitu sangat setuju $=4$, setuju $=3$, tidak setuju $=2$, sangat tidak setuju $=1$. Dari hasil yang sudah di isi oleh masing-masing ketua RT kemudian dilakukan perhitungan uji validitas dengan persamaan :

$$
r_{x y}=\frac{N \sum X Y-\left(\sum X\right)\left(\sum Y\right)}{\sqrt{\left\{N \sum x^{2}-\left(\sum y\right) 2-\left(\sum y\right)^{2}\right\}\left\{N \sum Y^{2}-\sum X^{2}\right\}}}
$$

Keterangan :

$\mathrm{X}=$ pertanyaan ke $-\mathrm{i}$ dari hasil kuisioner

$\mathrm{Y}=$ jumlah dari hasil keseluruhan kuiosioner

Tabel 3 Uji Validasi Kriteria

\begin{tabular}{|c|c|c|c|c|c|c|c|c|c|c|}
\hline $\mathrm{R} / \mathrm{K}$ & $\mathrm{K} 1$ & $\mathrm{~K} 2$ & $\mathrm{~K} 3$ & $\mathrm{~K} 4$ & $\mathrm{~K} 5$ & $\mathrm{~K} 6$ & $\mathrm{~K} 7$ & $\mathrm{~K} 8$ & $\mathrm{~K} 9$ & $\mathrm{~K} 10$ \\
\hline 1 & 2 & 3 & 3 & 3 & 2 & 4 & 2 & 3 & 2 & 2 \\
\hline 2 & 2 & 1 & 3 & 1 & 3 & 3 & 3 & 2 & 3 & 1 \\
\hline 3 & 2 & 1 & 3 & 1 & 2 & 2 & 3 & 3 & 1 & 2 \\
\hline 4 & 1 & 1 & 3 & 1 & 3 & 3 & 2 & 2 & 1 & 3 \\
\hline 5 & 4 & 4 & 3 & 3 & 3 & 3 & 3 & 3 & 2 & 2 \\
\hline 6 & 4 & 2 & 4 & 2 & 3 & 3 & 4 & 3 & 3 & 3 \\
\hline 7 & 3 & 2 & 4 & 2 & 4 & 2 & 3 & 3 & 4 & 4 \\
\hline 8 & 3 & 2 & 4 & 2 & 2 & 3 & 3 & 4 & 3 & 3 \\
\hline 9 & 2 & 1 & 2 & 1 & 1 & 4 & 1 & 3 & 4 & 3 \\
\hline 10 & 3 & 2 & 3 & 2 & 4 & 4 & 4 & 2 & 4 & 2 \\
\hline $\mathrm{Rh}$ & $\mathbf{0 . 8 7 5}$ & $\mathbf{0 . 6 7 5}$ & $\mathbf{0 . 6 3 4}$ & $\mathbf{0 . 7 3 3}$ & $\mathbf{0 . 5 1 1}$ & $\mathbf{0 . 0 2 9}$ & $\mathbf{0 . 6 0 3}$ & $\mathbf{0 . 3 4 7}$ & $\mathbf{0 . 5 2 1}$ & $\mathbf{0 . 3 2 3}$ \\
\hline $\mathrm{Rt}$ & $\mathbf{0 . 6 3 2}$ & $\mathbf{0 . 6 3 2}$ & $\mathbf{0 . 6 3 2}$ & $\mathbf{0 . 6 3 2}$ & $\mathbf{0 . 6 3 2}$ & $\mathbf{0 . 6 3 2}$ & $\mathbf{0 . 6 3 2}$ & $\mathbf{0 . 6 3 2}$ & $\mathbf{0 . 6 3 2}$ & $\mathbf{0 . 6 3 2}$ \\
\hline & Valid & Valid & Valid & Valid & Tidak & Tidak & Tidak & Tidak & Tidak & Tidak \\
\hline
\end{tabular}


Hasil yang didapatkan dari tabel 2, dikatakan valid dan tidak valid menggunakan nilai $\mathrm{r}$ tabel $=0,632$ dengan alpha $5 \%$.

\subsection{Multi Attribute Utility Theory (MAUT)}

Metode multi attribute utility theory merupakan salah satu metode dalam sistem pendukung keputusan untuk mengindentifikasi dan menggali informasi tentang prefrensi pengguna dalam konteks persolan[12]. Metode multi attribute utility theory juga merupakan suatu metode yang menilai skema evaluasi suatu produk berdasarkan attribute dan dimensi yang dimiliki[13][14].

Menghitung total dari bobot jumlah element / kriteria menggunakan persamaan (2) di bawah ini :

$\sum_{i=1}^{n} w i=1$

(2)

Melakukan normalisasi matriks menggunakan persamaan (3) di bawah ini :

$U_{(x)}=\frac{x-x i^{-}}{x i^{+}-x i^{-}}$

(3)

Menghitung nilai evaluasi menggunakan persamaan (5) di bawah ini :

$v(x)=\sum_{i=1}^{n} \operatorname{wivi}(x)$

Keterangan

$v(x) \quad=$ nilai evaluasi dari sebuah objek ke $i$

wi = bobot yang menentukan nilai dari seberapa penting elemen ke $i$ terhadap elemen lainnya

$\mathrm{n} \quad=$ jumlah element

$v i \quad=$ nilai keseluruhan dari alternative pilihan suatu kriteria.

Dari uraian persamaan di atas dapat di gambarkan pada gambar 2 di bawah ini :

Menguraikan sebuah keputusan ke dimensi berbeda Menentukan bobot relatif pada
masing-masing dimensi

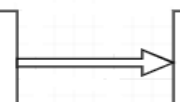

Data Alternaif

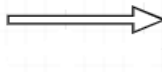

Mengalikan nilai utility dengan bobot masing-masing alternat

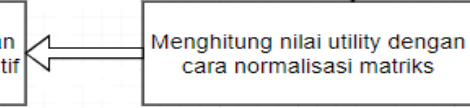

Gambar 2. Langkah-Langkah Metode Multi Attribute Utility Theory 


\section{HASIL DAN PEMBAHASAN}

\subsection{Kriteria}

Dari hasil uji validitas yang didapatkan, terdapat 4 kriteria yang valid yaitu, penghasilan, fasilitas air bersih, jumlah tanggungan dan luas bangunan. Selanjutnya dari kriteria tersebut di beri bobot, pembobotan kriteria menggunakan persamaan (2). Bobot kriteria dapat dilihat pada tabel 3 di bawah ini :

Tabel 4 Bobot Kriteria

\begin{tabular}{|c|l|c|}
\hline No & Nama Kriteria & Bobot \\
\hline 1 & Penghasilan & 0,4 \\
\hline 2 & Fasilitas Air Bersih & 0,2 \\
\hline 3 & Jumlah Tanggungan & 0,25 \\
\hline 4 & Luas Bangunan & 0,15 \\
\hline \multicolumn{2}{|c|}{$\sum$} & 1 \\
\hline
\end{tabular}

\subsection{Sub Kriteria}

a. Kriteria Penghasilan

Kriteria penghasilan dapat dilihat dari penghasilan masing-masing anggota $\mathrm{KK}$ yang menjadi kandidad penerima bantuan raskin. Pada kriteria penghasilan menjelaskan semakin besar penghasilan anggota KK, semakin kecil bobot yang diberikan.

Tabel 5 Sub Kriteria Penghasilan

\begin{tabular}{|c|c|c|}
\hline No & Sub Kriteria & Bobot \\
\hline 1 & $<$ Rp500.000 & 5 \\
\hline 2 & $>$ Rp500.000-Rp1.000.000 & 3 \\
\hline 3 & $>$ Rp. 1.000 .000 & 1 \\
\hline
\end{tabular}

b. Kriteria Fasilitas Air Bersih

Kriteria fasilitas air bersih dapat dilihat dari sumber air yang digunakan dari rumah masing-masing anggota KK yang menjadi kandidat penerima bantuan raskin. Pada kriteria fasilitas air bersih menjelaskan semakin susah air bersih yang didapatkan semakin besar bobot yang diberikan.

Tabel 6 Sub Kriteria Fasilitas Air Bersih

\begin{tabular}{|c|c|c|}
\hline No & Sub Kriteria & Bobot \\
\hline 1 & Sumur & 4 \\
\hline 2 & PDAM & 2 \\
\hline
\end{tabular}

c. Kriteria Jumlah Tanggungan

Kriteria jumlah tanggungan dapat dilihat dari jumlah anggota yang menjadi tanggung jawab masing-masing anggota KK. Pada kriteria jumlah tanggungan menjelaskan semakin banyak anggota keluarga pada KK semakin besar bobot yang diberikan.

Tabel 7 Sub Kriteria Jumlah Tanggungan

\begin{tabular}{|c|c|c|}
\hline No & Sub Kriteria & Bobot \\
\hline 1 & $\geq 5$ & 5 \\
\hline 2 & $3-4$ & 3 \\
\hline 3 & $\leq 2$ & 1 \\
\hline
\end{tabular}


d. Kriteria Luas Bangunan

Kriteria luas bangunan dapat diliat dari luas bangunan rumah masing-masing anggota KK. Pada kriteria luas bangunan ini menjelaskan semakin luas bangungan rumah semakin kecil bobot yang diberikan.

Tabel 8 Sub Kriteria Luas Bangunan

\begin{tabular}{|c|c|c|}
\hline No & Sub Kriteria & Bobot \\
\hline 1 & $\leq 8 \mathrm{M}^{2}$ & 5 \\
\hline 2 & $\geq 9-12 \mathrm{M}^{2}$ & 3 \\
\hline 3 & $\geq 13 \mathrm{M}^{2}$ & 1 \\
\hline
\end{tabular}

\subsection{Bobot Kriteria dan Sub Kriteria}

Dari data kriteria dan sub kriteria serta bobot yang sudah di dapatkan maka langkah selanjutnya di lakukan analisa perhitungan menggunakan metode multi attribute utility theory. Data kriteria dan sub kriteria yang terbobot dapat dilihat pada tabel 8 di bawah ini :

Tabel 9 Kriteria dan Sub Kriteria

\begin{tabular}{|c|c|c|c|c|}
\hline No & Nama Kriteria & Bobot & Sub Kriteria & Bobot \\
\hline \multirow[t]{3}{*}{1} & \multirow{3}{*}{ Penghasilan } & \multirow{3}{*}{0,4} & $<\mathrm{Rp} 500.000$ & 5 \\
\hline & & & >Rp500.000-Rp1.000.000 & 3 \\
\hline & & & $>$ Rp.1.000.000 & 1 \\
\hline \multirow[t]{2}{*}{2} & \multirow{2}{*}{ Fasilitas Air Bersih } & \multirow[t]{2}{*}{0,2} & Sumur & 4 \\
\hline & & & PDAM & 2 \\
\hline \multirow{3}{*}{3} & \multirow{3}{*}{ Jumlah Tanggungan } & \multirow{3}{*}{0,25} & $\geq 5$ & 5 \\
\hline & & & $3-4$ & 3 \\
\hline & & & $\leq 2$ & 1 \\
\hline \multirow{3}{*}{4} & \multirow{3}{*}{ Luas Bangunan } & \multirow{3}{*}{0,15} & $\leq 8 \mathrm{M}^{2}$ & 5 \\
\hline & & & $\geq 9-12 \mathrm{M}^{2}$ & 3 \\
\hline & & & $\geq 13 \mathrm{M}^{2}$ & 1 \\
\hline
\end{tabular}

\subsection{Analisa Perhitungan Multi Attribute Utility Theory}

Pada tahap ini penulis melakukan simulasi dengan menggunakan data alternatif Rt.01, dari data tersebut nantinya didapatkan nilai max dan nilai min masing-masing alternatif kriteria. Data alternatif dan kriteria dapat dilihat pada tabel 10 di bawah ini :

Tabel 10. Data Alternatif dan Kriteria

\begin{tabular}{|l|c|c|c|c|}
\hline \multirow{2}{*}{ Alternatif } & \multicolumn{4}{|c|}{ Kriteria } \\
\cline { 2 - 5 } & Penghasilan & $\begin{array}{c}\text { Fasilitas Air } \\
\text { Bersih }\end{array}$ & $\begin{array}{c}\text { Jumlah } \\
\text { Tanggungan }\end{array}$ & Luas Bangunan \\
\hline Suhardi & 3 & 4 & 5 & 3 \\
\hline Ahmadi & 1 & 4 & 5 & 3 \\
\hline Rahmat & 5 & 4 & 5 & 1 \\
\hline Eva & 3 & 2 & 3 & 1 \\
\hline Endang & 3 & 2 & 3 & 5 \\
\hline Edi & 5 & 4 & 1 & 1 \\
\hline Ariyandie & 3 & 2 & 1 & 5 \\
\hline Solimin & 3 & 4 & 3 & 1 \\
\hline Siti & 1 & 4 & 3 & 3 \\
\hline Pranita & 1 & 2 & 5 & 5 \\
\hline Hengki & 5 & 2 & 3 & 1 \\
\hline Julianti & 3 & 2 & 5 & 3 \\
\hline Rini & 1 & 4 & 3 & \\
\hline
\end{tabular}




\begin{tabular}{|l|l|l|l|l|}
\hline Suharti & 3 & 4 & 3 & 3 \\
\hline Bella & 1 & 2 & 1 & 3 \\
\hline Yudi & 1 & 2 & 1 & 1 \\
\hline Topan & 5 & 4 & 3 & 3 \\
\hline Guntur & 5 & 2 & 1 & 5 \\
\hline Ansori & 1 & 4 & 3 & 1 \\
\hline Mirza & 3 & 2 & 5 & 3 \\
\hline max & $\mathbf{5}$ & $\mathbf{4}$ & $\mathbf{5}$ & $\mathbf{5}$ \\
\hline min & $\mathbf{1}$ & $\mathbf{2}$ & $\mathbf{1}$ & $\mathbf{4}$ \\
\hline selisih & $\mathbf{4}$ & $\mathbf{2}$ & $\mathbf{4}$ & $\mathbf{4}$ \\
\hline
\end{tabular}

Setelah data aternatif dan kriteria didapatkan, maka langkah selajutnya melakukan normalisasi matriks dengan menggunakan persamaan (3).

1. Nama Alternatif Suhardi, Kriteria Penghasilan Suhardi,penghasilan $\quad=\frac{3-1}{5-1}=0,5$

2. Nama Alternatif Suhardi, Kriteria Fasilitas air bersih Suhardi,fasilitas air bersih $\quad=\frac{4-2}{4-2}=1$

3. Nama Alternatif Suhardi, Kriteria Jumlah Tanggungan Suhardi,jumlah Tanggungan $=\frac{5-1}{5-1}=1$

4. Nama Alternatif Suhardi, Kriteria Luas Bangunan Suhardi,luas bangungan $\quad=\frac{3-1}{5-1}=0,5$

Hasil keseluruhan normalisasi matriks dapat dilihat pada tabel 11 di bawah ini :

Tabel 11 Hasil Normalisasi Matriks

\begin{tabular}{|l|c|c|c|c|}
\hline \multirow{2}{*}{ Alternatif } & \multicolumn{4}{c|}{ Kriteria } \\
\cline { 2 - 5 } & Penghasilan & $\begin{array}{c}\text { Fasilitas Air } \\
\text { Bersih }\end{array}$ & $\begin{array}{c}\text { Jumlah } \\
\text { Tanggungan }\end{array}$ & Luas Bangunan \\
\hline Suhardi & 0.5 & 1 & 1 & 0.5 \\
\hline Ahmadi & 0 & 1 & 1 & 0.5 \\
\hline Rahmat & 1 & 1 & 1 & 0 \\
\hline Eva & 0.5 & 0 & 0.5 & 0 \\
\hline Endang & 0.5 & 0 & 0.5 & 0.5 \\
\hline Edi & 1 & 1 & 0 & 0 \\
\hline Ariyandie & 0.5 & 0 & 0 & 1 \\
\hline Solimin & 0.5 & 1 & 0.5 & 0 \\
\hline Siti & 0 & 1 & 0.5 & 0.5 \\
\hline Pranita & 0 & 0 & 1 & 0.5 \\
\hline Hengki & 1 & 0 & 0.5 & 0 \\
\hline Julianti & 0.5 & 0 & 1 & 0.5 \\
\hline Rini & 0 & 1 & 0.5 & 0.5 \\
\hline Suharti & 0.5 & 1 & 0.5 & 0 \\
\hline Bella & 0 & 0 & 0 & 0.5 \\
\hline Yudi & 0 & 0 & 0 & 1 \\
\hline Topan & 1 & 1 & 0.5 & 0 \\
\hline Guntur & 1 & 0 & 0 & 0.5 \\
\hline Ansori & 0 & 1 & 0.5 & 1 \\
\hline Mirza & 0.5 & 0 & & \\
\hline
\end{tabular}

Langkah selanjutnya melakukan melakukan perhitungan untuk mendapatkan nilai evaluasi, yang mana nilai evaluasi tersebut menjadi acuan dalam perangkingan. Perhitungan nilai evaluasi menggunakan persamaan (4).

1. Suhardi $=(0.5 * 0.4)+(1 * 0.2)+(1 * 0.25)+(0.5 * 0.15)=0.725$

2. Ahmadi $=(0 * 0.4)+(1 * 0.2)+(1 * .025)+(0.5 * 0.15)=0.525$ 
3. Rahmad

$$
=(1 * 0.4)+(1 * 0.2)+(1 * 0.25)+(0 * 0.15)=0.85
$$

Hasil keseluruhan nilai evaluasi dapat diliat pada tabel 12 di bawah ini :

Tabel 12 Nilai Evaluasi / Perangkingan

\begin{tabular}{|l|l|c|}
\hline No & Nama Alternatif / KK & Evaluasi \\
\hline 1 & Suhardi & 0.725 \\
\hline 2 & Ahmadi & 0.525 \\
\hline 3 & Rahmat & 0.85 \\
\hline 4 & Eva & 0.325 \\
\hline 5 & Endang & 0.4 \\
\hline 6 & Edi & 0.75 \\
\hline 7 & Ariyandie & 0.2 \\
\hline 8 & Solimin & 0.675 \\
\hline 9 & Siti & 0.325 \\
\hline 10 & Pranita & 0.325 \\
\hline 11 & Hengki & 0.675 \\
\hline 12 & Julianti & 0.525 \\
\hline 13 & Rini & 0.325 \\
\hline 14 & Suharti & 0.6 \\
\hline 15 & Bella & 0.075 \\
\hline 16 & Yudi & 0 \\
\hline 17 & Topan & 0.8 \\
\hline 18 & Guntur & 0.55 \\
\hline 19 & Ansori & 0.325 \\
\hline 20 & Mirza & 0.525 \\
\hline
\end{tabular}

Dari hasil $20 \mathrm{KK}$ di atas maka, selanjutnya melihat nilai tertinggi, pada hasil wawancara sebelumnya ada 10 nama KK yang berhak untuk mendapatkan bantuan raskin, dimana ke $10 \mathrm{KK}$ tersebut dilihat dari nilai tertinggi / perangkingan dari nilai evaluasi. Berikut 10 nama KK yang mendapatkan bantuan raskin dengan menggunakan metode multi attribute utility theory.

Tabel 13 Perangkingan

\begin{tabular}{|l|l|c|}
\hline No & Nama Alternatif / KK & Evaluasi \\
\hline 1 & Rahmat & 0.85 \\
\hline 2 & Topan & 0.8 \\
\hline 3 & Edi & 0.75 \\
\hline 4 & Suhardi & 0.725 \\
\hline 5 & Solimin & 0.675 \\
\hline 6 & Hengki & 0.675 \\
\hline 7 & Suharti & 0.6 \\
\hline 8 & Guntur & 0.55 \\
\hline 9 & Mirza & 0.525 \\
\hline 10 & Ahmadi & 0.525 \\
\hline
\end{tabular}

\section{KESIMPULAN}

Dari hasil penelitian ini kesimpulan yang dapat ditarik adalah:

1. Data yang digunakan untuk perhitungan menggunakan metode MAUT merupakan data RT.01 
2. Hasil uji validasi di dapatkan 4 kriteria valid yang akan digunakan, yakni, penghasilan, fasilitas air bersih, jumlah tanggungan, dan luas bangunan.

3. Berdasarkan perhitungan nilai evaluasi, nilai tertinggi adalah yang berhak menerima bantuan raskin.

\section{DAFTAR PUSTAKA}

[1] J. Jamhari, "Efektivitas Distribusi Raskin Di Pedesaan Dan Perkotaan Indonesia," J. Ekon. Pembang. Kaji. Masal. Ekon. dan Pembang., vol. 13, no. 1, p. 132, 2012.

[2] Bulog, "Sekilas Raskin," 2019. [Online]. Available: bulog.co.id/sekiilas_raskin.php.

[3] Y. Primadasa and H. Juliansa, "Penerapan Metode Vikor dalam Seleksi Penerimaan Bonus Pada Salesman Indihome," Digit. Zo. J. Teknol. Inf. dan Komun., vol. 10, no. 1, pp. 33-43, 2019.

[4] M. Hidayat and P. A. Jusia, "Analisa dan Perancangan Sistem Pendukung Keputusan Untuk Penerimaan Karyawan PT . Dos Ni Roha Jambi Menggunakan Metode MAUT ( Multi Attribute Utility Theory )," PROCESSOR, vol. 13, no. 1, 2018.

[5] N. Hadinata, "Implementasi Metode Multi Attribute Utility Theory (MAUT) Pada Sistem Pendukung Keputusan dalam Menentukan Penerima Kredit," SISFOKOM, vol. 07, no. September, pp. 87-92, 2018.

[6] R. Ramadiani and A. Rahmah, "Sistem keputusan pemilihan tenaga kesehatan teladan menggunakan metode Multi-Attribute Utility Theory," Regist. J. Ilm. Teknol. Sist. Inf., vol. 5, no. 1, p. 1, 2018.

[7] D. Fajirwan, M. Arhami, and I. Amalia, "Sistem Pendukung Keputusan Penerimaan Bantuan Renovasi Rumah Dhuafa Menggunakan Metode Multi Attribute Utility Theory," J. Infomedia, vol. 3, no. 2, pp. 49-57, 2018.

[8] R. N. Sari and R. S. Hayati, "Penerapan Metode Multi Attribute Utility Theory (MAUT) Dalam Pemilihan Rumah Kost," J-SAKTI (Jurnal Sains Komput. dan Inform., vol. 3, no. 2, p. 243, 2019.

[9] D. A. Ridwan and B. Rahman, "PENENTUAN PENERIMAAN RASKIN ( BERAS MISKIN ) PADA KECAMATAN KENDARI BARAT MENGGUNAKAN METODE ANALYTHICAL HIERARCHI PROCESS ( AHP )," vol. 4, no. 1, pp. 25-31, 2019.

[10] P. Wolo, A. S. M. Paseng, and Y. W. Roberth, "Sistem Pendukung Keputusan Penentuan Penerimaan Raskin Menggunakan Metode Simple Additive Weighting (Studi Kasus Kelurahan Kota Uneng)," Teknika, vol. 8, no. 1, pp. 74-77, 2019.

[11] E. Satria, N. Atina, M. E. Simbolon, and A. P. Windarto, "Spk: Algoritma Multi-Attribute Utility Theory (Maut) Pada Destinasi Tujuan Wisata Lokal Di Kota Sidamanik," Comput. Eng. Sci. Syst. J., vol. 3, no. 2, p. 168, 2018.

[12] R. Ramadiani and A. Rahmah, "Sistem pendukung keputusan pemilihan tenaga kesehatan teladan menggunakan metode Multi-Attribute Utility Theory," Regist. J. Ilm. Teknol. Sist. Inf., vol. 5, no. 1, p. 1, 2019.

[13] D. Ilmu, K. Informatika, and U. Diponegoro, "Sistem pendukung keputusan 
penentuan nilai kenaikan pangkat tni angkatan darat menggunakan metode composite performance index (cpi) 1,2," pp. 102-108.

[14] T. Imandasari, A. P. Windarto, and D. Hartama, "Analisis Metode MAUT Pada Pemilihan Deodorant," SAINTEKS, pp. 736-739, 2019. 